Cuestiones de filosofía

ISSN: 0123-5095

Vol. 1 - No. 17

Año 2015

pp. $193-208$

\title{
CUERPO Y ESCRITURA ARTAUD Y LA EXPERIENCIA TARAHUMARA
}

\author{
The body and writing Artaud and \\ the Tarahumara Experience
}

Johan Camilo Sánchez-Medina

sanchez.johan@urosario.edu.com

Universidad del Rosario (Colombia)

Fecha de recepción: 11/11/ 2014

Fecha de evaluación: 24/02/2015

Fecha de aprobación: 15/09/2015

\section{Resumen}

Este ensayo hace una lectura conceptual del texto Los Tarahumaras, de Antonin Artaud, y explora una forma en la que dicho relato pueda traducirse en conceptos. El problema: cómo es posible concebir una noción de cultura que no se confunda con civilización y que, a su vez, indique un camino nuevo para la experimentación artística. Se propone un motivo político para analizar el viaje de Artaud a tierras mexicanas, y hecho esto se abre paso al análisis del relato y del concepto que él mismo construye. Finalmente, se desarrolla la siguiente hipótesis: en la experimentación con el peyote y la ceremonia ritual, Artaud arriesga una forma de resistencia que al autor de este ensayo le gustaría llamar política experimental. La pregunta que guía la hipótesis es cómo la experiencia tarahumara inscribe una huella de tal intensidad en la conciencia de Artaud que, por largo tiempo, va a incidir en la producción de su escritura.

Palabras clave: Arte, Artaud, Experimentación artística,Poesía, Tarahumaras. 


\begin{abstract}
This paper makes a conceptual reading of the text The Tarahumara, written by Antonin Artaud, and explores a way in which this story can be translated into concepts. The problem: how possible is to conceive a notion of culture that is not confused with civilization and that, in turn, provides a new way to the artistic experimentation. It proposes a political motive to analyze the journey of Artaud on the Mexican soil, and once it is done, it opens to the story and the concept analysis built by himself. Finally, it is developed the following hypothesis: in the experimentation with the peyote and the ritual ceremony, Artaud risks a form of resistance that I'd call experimental policy. The question that guides the hypothesis, is how the tarahumara experience inscribes a mark with such intensity in the consciousness of Artaud that, for a long time, it is going to influence his writing production.
\end{abstract}

Keywords: Arte, Artaud, Artistic experimentation, Poetry, Tarahumaras.

\title{
1. Consideraciones Preliminares
}

Nunca la civilización estuvo tan consagrada a idealizar una cultura global. Nunca, tanto como ahora, la comunicación se había convertido en un ámbito absolutamente indispensable para la reflexión política sobre la cultura. El espíritu de una época ha buscado reproducir un cierto ideal de lo humano como principio organizador del mundo. Los más diversos grupos sociales se ven incorporados en la dinámica de su sistema: parámetros normativos e institucionales ordenan el conjunto de lo social y las funciones del Estado. Los sistemas de producción, los canales de información masiva, los medios tecnológicos de divulgación de la información y la incorporación institucional de grupos étnicos en sistemas democráticos han fijado un panorama ideal de sociedades razonables.

La civilización occidental ha justificado esa idea acudiendo a símbolos que se han ido afianzando por la fuerza modélica de su misma tradición. Los símbolos se han convertido en ídolos, y los ídolos, en regímenes de la vida social, familiar, económica, política y espiritual. La fuerza social de esos símbolos ha permitido configurar los sentimientos morales de jerarquía, de ley, de mandato y de finalidad que, con la expansión del capitalismo, no han dejado de intervenir en la construcción delas instituciones de las sociedades occidentales y de muchas de las comunidades no occidentales. El símbolo que concita todos los demás alrededor de los ideales 
humanistas es justamente el de Hombre. A través de la noción de Hombre se mantiene la idea según la cual la cultura es un producto del programa de una razón civilizada que, además de aplicar su plan de organización al conjunto de lo social, también determina la construcción de sujetos funcionales para su aparato de reproducción. Lo que ocurrió con la cultura también ocurrió con el arte. Dentro de las sociedades occidentales el arte se volvió un medio más de comunicación y de entretenimiento que terminó porempobrecer la experiencia estética.

Aunque sin las consecuencias sistémicas que hoy podemos deducir, algunos jóvenes artistas de vanguardia, de primera mitad del siglo XX, intuyeron un problema radical en esa modelización de la cultura que arrastraba tras de sí gran parte de la producción artística; es lo que se ha llamado la generación de las vanguardias, entre ellas el surrealismo. Al abrigo del surrealismo surgió Antonin Artaud ${ }^{1}$; su pensamiento estéticoy su labor poética y teatral van de la mano con la posibilidad de explorar nuevas potencias, nuevas formas para concebir el acontecimiento de la vida y el acontecimiento radical del arte. Artaud se puso ‘en guerra' contra los principios morales que decían cómo vivir en la Europa de los años veinte; estaba harto de las prescripciones de la familia y de la moral social; sentía hastío por los partidos políticos, y si bien declaraba una simpatía profunda por la revolución, estaba en contra del arte como forma de expresión partidista. Esta es una de las razones por las que Artaud se desprende del movimiento surrealista, que ya por 1926 militaba junto al comunismo. Para él, esta forma de revolución también imponía un ideal de cultura y civilización, porque justamente sacaba provecho de su contenido: "Lo que nos ha hecho perder la cultura es nuestra idea occidental del arte y el provecho que de ella obtenemos. ¡Arte y cultura no pueden ir de acuerdo, contrariamente al uso que de ellos se hace universalmente!" (Artaud, 1999: 13). Si traducimos cultura por civilización occidental, este será uno de los tantos gritos de resistencia frente a las formas civilizatorias que limitan las potencias de la vida y definen la 'función social' del arte.

Ahora, la asimilación de la cultura occidental occidental como civilización universal resulta conflictiva en las sociedades coloniales, que, justamente, resisten a la civilización desde las culturas ancestrales. Por un lado, la civilización configura el prototipo de la idea de Hombre que hemos venido describiendo; por el otro, la

1 Sin duda, el contexto de la época está cargado de fuertes tensiones ideológicas que se desenvuelven en un escenario de entreguerras; esto indica ya el ambiente corrosivo dentro del que Artaud percibía la noción de Hombre. 
cultura que cultivan los pueblos originarios parece brotar de la naturaleza-hombre para mostrarla en relación permanente con el territorio. Sobre ese plano el hombreidea se resuelve en hombre-materia, en deseo y vida. Sin romanticismo y sin negar los matices y los equívocos que se derivan de la colonización, podríamos afirmar que la diferencia radica en el plano de inmanencia. En las culturas originarias, el plano de inmanencia, que viene a ser el lugar y el proceso de producción de la cultura, no se separa de la vida ni de su gestación. Las culturas indígenas permiten concebir en un mismo plano el proceso de nacimiento de diversas formas de vida, de símbolos y prácticas que no solamente operan en función de normas institucionalizadas, sino que sirven para producir otra cosmovisión del mundo, otros lenguajes que vienen a potenciar la riqueza estética de la naturaleza humana.

Imbuido de esa problemática, pero sobretodo con la certeza de que el problema se había convertido en un dilema por resolverse en su propio cuerpo, hacia 1936 Artaud emprende un viaje a tierras mexicanas, con la intención de explorar otras formas de cultura. El viaje de Artaud constituye cierto movimiento contracultural frente a la cultura heredada, en la medida en que, por primera vez, exponía todo su yo a un entorno totalmente nuevo. Artaud asume el viaje como si encarnara los ideales vanguardistas de la época, pero al mismo tiempo sabe que lo que está en juego es una transformación profunda de su propia subjetividad. El trabajo, decía, es "nada menos que romper con el espíritu de todo un mundo, y de reemplazar una civilización por otra” (Artaud, 1973: 92).

En ese propósito, a los ojos de Artaud, la sierra Tarahumara en México promete un territorio que guarda potencias, formas, símbolos, figuras, en fin, cosmovisiones que producen el nacimiento de otra vida cultural; potencias que vienen a descubrirse en un territorio americano que conserva otros lenguajes y otras prácticas sociales. Se trata de un territorio con una materia informe o, mejor, con una materia cósmica que actúa permanentemente en la producción ritual de la naturaleza como la expresión más alta de la organización social de la comunidad.

En lo que sigue, primero reconstruimos esta experiencia desde los textos de Artaud, y en la segunda parte proponemos la lectura de esta experiencia en términos estéticos. Siguiendo a Deleuze y Guattari, de lo que se trata, en el caso de los tarahumara, no es solamente del agenciamiento ritual de todo un socius que, afianzado en un territorio, crea signos y produce ritmos de tránsito, sino de la construcción de un Cuerpo sin Órganos $(\mathrm{CsO})$ con la tierra. Pero la composición del $\mathrm{CsO}$ también puede ser expresada como proceso de individuación, en este caso, como un ejercicio del 
propio Artaud en su experimentación con esas otras intensidades inorgánicas que se mueven en el ambiente de la Sierra. En ese ejercicio, el CsO-Artaud desterritorializa su propio organismo y cifra una multiplicidad de pulsiones en el territorio amerindio. Fabrica un devenir otro en clave ritual tarahumara. Lo que se agencia es un programa de política experimental en la que Artaud ofrece su propia individualidad mental y orgánica a esa suerte de sacrificio del sí mismo que significa la toma del peyote. En el territorio tarahumara, Artaud descubre una especie de principio geofísico que hacen brotar la vida de la Sierra, y experimenta una suerte de segundo nacimiento en una cultura absoluta extraña a su identidad europea. En la última parte se plantea sucintamente la continuidad entre la experiencia de Artaud y su concepción del teatro de la crueldad, tratando de mostrar lacontinuidad estética del viaje en su producción intelectual.

\section{La DANZa Del TUTUguri O CÓMO NACER EN OTRA CULTURA}

Como en muchas otras culturas amerindias, la inmersión en la cultura tarahumara viene acompañada de un ritual de iniciación. A través de ceremonias, de danzas y de la toma de sustancias alucinógenas, los indígenas tarahumaras incorporan un espíritu nuevo para ofrendarlo al poder místico del cosmos. La ofrenda consiste en sacrificar los malos espíritus del nuevo integrante; pero ofrendar sacrificialmente no significa en este caso el asesinato fisiológico del cuerpo, sino el ofrecimiento de un espíritu a la deidad, el cual se fusiona con la naturaleza en cada una de sus capas, para permitir la revitalización de ese mismo cuerpo en la estética espiritual de la comunidad. En el caso de Artaud, se trata justamente de la extirpación de esos símbolos corroídos y ya incorporados en la construcción de las subjetividades en Occidente, para el nacimiento del hombre-nuevo.

El mito de iniciación dentro de los tarahumaras es el mito del Misterio, y se consuma en la danza del Tutuguri; una danza hecha en honor a Ciguri: la deidad, el espíritu cósmico de la Sierra. En la danza hay dos principios que se manifiestan en agitación corporal; dos cuerpos/principios brotados de la "Madre Tierra": la Hembra y el Macho. Hembra y Macho ocupan el espacio indígena de la danza para descubrir el nacimiento de la vida, el autónomo nacimiento de los símbolos de la cultura.

El Hombre de los tarahumaras no es el Hombre-racional, sino el Hombre-increado, esto es, en proceso de creación; en su nacimiento, él ya implica su doble: machohembra, el cosmos-territorio, la noche-día. La danza macho-hembra, dice Artaud en su relato, "ocupa la noche entera, desde el crepúsculo hasta la aurora, pero coge toda 
la noche y la concentra, como cuando se toma todo el zumo de la fruta hasta la fuente de la vida. Y la extirpación de propiedades llega hasta dios y lo sobrepasa; pues dios, y sobre todo dios, no puede coger lo que en el yo es auténticamente el sí mismo por mucho que éste cometa la imbecilidad de abandonarse" (Artaud, 1977:10). Extirpación del organismo en el nacimiento de la vida animal. Devenir de la noche y el día, devenir del macho y la hembra: la aurora del nacimiento. Extirpación de la propia conciencia, disolución del yo en la muerte y en el cosmos libidinal de los cuerpos.

Para los tarahumaras, Artaud es un hombre cubierto de Malos Espíritus; es hombre blanco contaminado por símbolos que hacen del todo algo ya creado. El Mito del Misterio es un rito de exterminio. Jesús, Dios y el Verbo toman nuevo significado en la danza del Tutuguri. Para los sacerdotes tarahumaras ya no existe el mandato y las leyes de la creación, solo existe una sensación atmosférica con el Todo en nacimiento: Ciguri. De manera que "Los tarahumara no creen en Dios, y la palabra de Dios no existe en su lengua; pero rinden culto a un principio trascendente de la Naturaleza, que es Macho y Hembra, como debe ser" (1977: 73). La danza y el mito producen un primer exterminio: el juicio de Dios. Antonin Artaud es quien se expone en el rito para extirpar sus propios símbolos: "El espíritu del hombre - dice- está harto de Dios, porque es malo y está enfermo, y nosotros debemos devolverle el hambre" (1977: 12).

La danza adquiere toda su ritualidad en la toma de peyote. El peyote altera la conciencia porque recupera la verdadera percepción del infinito en el culto al Ciguri (1977: 1112). Ciguri es lo que se muestra en un acontecimiento inesperado y cósmico a los ojos de Artaud. "Yo" ya no es conciencia individual de imagen personalizada y sentimiento divino, sino conciencia de la multiplicidad de formas que se manifiestan en la danza y en el territorio, pues disponen de un medio material de expresión: la Sierra. De Ciguri proviene la sensación de potencias inscritas en la Sierra. El peyote lo que hace es despertar los sentidos de la conciencia en experiencia directa con ella; pero esta experiencia se produce sobre el plano de inmanencia; el plano donde la danza construye un territorio y donde viene a acontecer el nacimiento de la cultura. La relación indisociable que produce el peyote entre el medio (la Sierra) y la conciencia (Artaud) descubre esa manifestación de otros símbolos. En cierto modo, el peyote es un primer filtro para que el espíritu pueda renacer en otra colectividad; una colectividad en relación con el infinito: donde Ciguri es el Señor y Dueño de todas las cosas.

En cierto sentido, el cuerpo de Artaud se reterritorializa en el culto del peyote, permitiendo el despliegue de esos símbolos tan nuevos para él. El movimiento de territorialización supone ya toda una transformación del territorio habitado y, en 
consecuencia, toda una transformación de los símbolos de su conciencia. El símbolo Hombre deviene en el proceso del rito: "Ciguri, dicen, era el HOMBRE, tal como POR SÍ MISMO, ÉL mismo en el espacio SE construía, cuando Dios lo asesinó” (1977: 19). Eso que ha sido asesinado y que se ha construido es el propio Artaud durante el proceso de trance en la toma de peyote;se ha construido mediante el proceso de desprendimiento de sus símbolos: Padre, Madre y Cristo devienen Hombre Increado, sin sexo, sin organismo.

Ahora bien, el peyote es la sustancia que permite la entrada de Ciguri en el cuerpo de Artaud; es decir, el rito de la toma de peyote permite que, en el mismo trance, un espíritu cósmico disuelva la conciencia en ese plano de consistencia: el ritual. No es el Yo de Artaud quien recibe a Ciguri, sino que es su cuerpo el que lo experimenta a través del peyote. Poco a poco la cultura tarahumara se va manifestando en el cuerpo de Artaud como erigiendo un tótem simbólico y espiritual. Entiendotótem como la expresión material de la voluntad autopoiética de una cultura; es una voluntad organizada socialmente que también es cognitiva: "el tarahumara distingue sistemáticamente entre lo que es de él y lo que es del Otro en todo lo que piensa, siente y produce" (1977: 14). Por eso, lo que se produce en Artaud depende de lo Otro; pero eso Otro es lo que produce vida dentro de la cultura tarahumara, como voluntad dispuesta ya de antemano por Ciguri.

En síntesis, dentro de la tradición tarahumara, el peyote es el Hombre: el Hombre Innato, el Hombre todavía no nacido (1977: 26); aquí el hombre todavía no es consciente. El peyote produce una especie de abandono inconsciente del cuerpo; sin embargo, el inconsciente parece adquirir una fuerza de conciencia en las alucinaciones. Las alucinaciones no son imágenes aprehendidas, sino sensaciones de formas, de potencias que se manifiestan desde el territorio donde mora el cuerpo de Artaud; en otras palabras, el Doble es quien despliega la percepción fundida en el infinito de la naturaleza; el Doble es el Otro: es la fuerza, es la pulsión autónoma de producción. El peyote es justamente la sustancia inorgánica que produce en la conciencia un haz diverso de impresiones; todo lo que existe se manifiesta gracias a esa percepción "recuperada", como si el peyote revelara el momento en que nada es real y, sin embargo, todo es verdadero en el cosmos del Ciguri. Una religiosidad distinta hace que la naturaleza se manifieste bajo formas contenidas en la expresión de Signos en proceso de creación, porque justamente no están creados previamente ni por Dios, ni por el Padre, ni por Cristo. "Quiero decir que, aunque una nueva y última vez a imponerse a mi pensamiento, el Peyote, EN CAMBIO, no se presta a esas fétidas asimilaciones espirituales, pues la MÍSTICA no ha sido nunca otra cosa 
que una copulación de una hipocresía muy sabia y refinada contra la cual el PEYOTE todo entero protesta, pues con él EL HOMBRE está solo, y tocando desesperadamente la música de su esqueleto, sin padre, madre, amor, dios o sociedad" (1977: 26).

\section{El Peyote y la construcción del Cuerpo sin Órganos}

El texto Los tarahumaras también puede ser leído como un texto etnográfico. El rito de la toma de peyote, dice Artaud, debe desarrollarse con cierta prudencia; cada taza debe tomarse en las medidas indicadas por los sacerdotes que presiden la ceremonia; la experiencia enseña que el abuso en la dosis impide la llegada del Ciguri en el cuerpo, o permite la intromisión de los fantasmas, de malos espíritus o de símbolos déspotas. En cambio, la ritualidad de la danza y la toma de peyote en su justa medida producen el nacimiento de un doble, la conciencia ya poseída por el misterio del Cosmos. En su caso, cuando el Ciguri penetra en el cuerpo, la conciencia de Artaud trabaja en extirpar los Malos Espíritus, en destruirlos hasta que sus fantasmas son expulsados por obra del Ciguri.

La disolución de la conciencia provocada por la entrada de Ciguries orgánica, pero su efecto es inorgánico. El órgano que filtra el peyote es precisamente el hígado: "Ahí es donde el Yo se vuelve consciente y despliega su poder de apreciación, de discriminación orgánica extrema. Porque es en él donde Ciguri realiza su trabajo de separar lo que existe de lo que no existe" (1977: 28). El hígado es el depósito orgánico donde se produce el acontecimiento de la mutación inorgánica. La toma de peyote y el recibimiento del Ciguri permite que todas las fuerzas de la Tierra y del rito tarahumara modifiquen el espíritu material de Artaud a través de sus órganos. Por eso es que el agenciamiento es doloroso. Asíes como se expresa en el relato:

No renuncié de una vez a todas aquellas disociaciones que el Peyote provoca, al parecer, y que había estado buscando durante veinte años; no subía un caballo con un cuerpo arrancado a sí mismo y al que la supresión a la que me había entregado privaba en delante de sus reflejos esenciales; no había pasado por aquel estado de hombre petrificado que necesitaba dos hombres para montar; $y$ al que montaban y bajaban del caballo como a un autómata desamparado, y, cuando iba a caballo, me ponían las manos en las bridas, y tenían, además, que cerrarme los dedos en torno a las bridas, pues estaba claro que había perdido la libertad para hacerlo por mí mismo; no había vencido a fuerza de voluntad aquella hostilidad orgánica, que hacía que fuera yo quien me negaba a andar, para traer 
una colección de imágenes caducas, de las que la Época, fiel en ello a todo un sistema, sacaría como máximo ideas para carteles y modelos para sus modistas. En adelante era necesario que esa cosa escondida tras aquella trituración pesada que emparejaba el alba con la noche quedase al descubierto y sirviese, sirviese precisamente gracias a mi crucifixión (1977: 51/52).

En la toma de peyote, el organismo, entendido como dispositivo de subjetivación, atraviesa un proceso de crucifixión. La crucifixión de Artaud no hace alegoría al sufrimiento de Jesucristo. La crucifixión de Artaud es el sacrificio de sus órganos en la experiencia directa con el peyote. La percepción recuperada en su toma despliega todo un movimiento dinámico de pulsiones, de fuerzas que atraviesan el cuerpo de Artaud recomponiéndolo; ese cúmulo de fuerzas produce una transformación interna. Un dinamismo interno disloca la conciencia para abrirla al cosmos de la Sierra. El organismo hace ebullición a través del hígado al entrar en el rigor de los pasos y los signos cifrados del ritual.

En cierto sentido, Artaud promueve una especie de asesinato de sus órganos en la toma de peyote, pero el ritual sacrificial lo ofrece la comunidad. Asíque Artaud libra una batalla con los símbolos que se materializan en la transmutación de sus órganos, pero en el momento de la donación colectiva. El cuerpo es el umbral por donde atraviesan conexiones, conjuntos, materias no formadas. Artaud arranca la conciencia de "yo" para convertirla en un medio de exploración; arranca el inconsciente de cualquier tipo de interpretación para hacerlo producir en un territorio (Deleuze \& Guattari, 2010: 165). En síntesis, el agenciamiento de Artaud fabrica, literalmente, un Cuerpo Sin Órganos (CsO).

Mientras más profundidad alcance el Doble, más disolución de símbolos, más contacto directo con Ciguri, más experiencia directa con la cultura tarahumara. El Cuerpo Sin Órganos es fabricado prudentemente, pero, aun así, Artaud vacía todo lo que dentro de él pueda resguardar Organismo; precisamente, agencia unprograma en donde se despliega el sí mismo como multiplicidad sobre el territorio ritual; el programa opera en un proceso de composición; Artaud agencia un programa de composición múltiple². El CsO es un componente que permite el flujo de un

2 Aun con todo, el CsO de Artaud surge de una necesidad que coincide con la necesidad de toda una juventud de la época; en cierto modo, se trata de un movimiento colectivo del arte de vanguardia, pero no solo eso, en parte también se debe a que los jóvenes artistas europeos buscaban un medio más prolífico para la experimentación artística, y, sin duda, produjo varios frutos en relación con el teatro, la poesía, la literatura, la pintura y el cine. 
cúmulo de intensidades producidas por la colectividad tarahumara, $\mathrm{y}$, sin duda,su hígado es el filtro experimental que le permite nacer en esa otra cultura. En palabras de Deleuze y Guattari: "Es cierto que Artaud libra una batalla con los órganos, pero al mismo tiempo está contra el organismo, su enemigo es el organismo [...]. El CsO no se opone a los órganos, sino que, con sus 'órganos verdaderos', que deben ser compuestos y situados, se opone al organismo, a la organización orgánica de los órganos" (2010: 163).

En esa des/recomposición, el CsO se resiste a toda la organización subjetiva y sexual del cuerpo; en esto radica el agenciamiento contracultural. Artaud deshace su Yo junto con los símbolos heredados de la cultura europea, pero la declaración de guerra, a través del peyote, es también un programa del $\mathrm{CsO}$ que va gestando su propio plano de inmanencia: repoblación de sensaciones y desmultiplicación de la libido en el cuerpo a través de la percepción del infinito. El plano de inmanencia se construye con el programa y con el transitar de Artaud a través de la Sierra; el plano de inmanencia se despliega por ese dinamismo internoexpuesto al entorno tarahumara. Deseo de experiencia, hambre de vida y dolor visceral; se trata de pulsiones que desarrollan todo un programa contracultural como proceso de desterritorialización y de reterritorialización: Artaud está deshaciendo su composición orgánica en un plan de consistencia que es el CsO y está descubriendo un nuevo plano de inmanencia para el pensamiento. El plan de consistencia es el modo en que se generan las conexiones del CsO; así, mientras transita el territorio no deja de deshacer el organismo para producir su CsO. A su vez, ese sacrificio permite la entrada del espíritu que los tarahumara llaman Ciguri, de modo que el CsOes "poblado por [las] intensidades" (2010: 158) de un plano de inmanencia cósmico donde renace a las potencias originarias del cuerpo y el pensamiento.

\section{Del CsO a la PRoliferación maQuínica: Signos y Figuras}

La naturaleza de la Sierra está llena de signos. El territorio tarahumara produce signos autóctonos que proliferan en la estética de sus montañas. Los signos se manifiestan en formas geográficas: el territorio, literalmente, se expresa; se muestran formas en movimiento constante y con expresiones permanentes: las rocas en su relieve, el contraste de la luz que las alumbra, el contraste de sombra que cobija las rocas en medio de la montaña, la hendidura de la tierra que se muestra en su pliegue. Los pliegues se producen por estratos: son distribuciones móviles de las materias y de las formas que de manera multiplicada brotan del territorio. Las formas y las

materias configuran símbolos que, simultáneamente, se producen por los pliegues 
de una materia viva en el Cosmos: "esa Naturaleza ha querido pensar como un hombre. De la misma forma que ha evolucionado a unos hombres, así también ha evolucionado a unas rocas" (1977: 36). El Hombre, como principio que se manifiesta en la danza del peyote, cobra vida en toda la geografía de la Sierra. El Hombre y la naturaleza se expresan uno dentro del otro en un solo ritmo: Ciguri; un juego de multiplicidades actuando sobre otras multiplicidades.

Ahora bien, el relato de Artaud nos permite diagramatizar o trazar una suerte de mapa del agenciamiento: una línea de expresión perceptiva que puede guiarnos en su escritura para mostrar cómo se manifiestan estas formas. Sin duda, la composición del CsO es también el despliegue de un agenciamiento que acontece en el territorio habitado. En su recorrido, a medida que construye el $\mathrm{CsO}$ para rehacer su cuerpo, Artaud va modificando el territorio de la Sierra, produce marcas estéticas, altera los registros perceptivos, traza de nuevo el camino transitado. La Sierra y Artaud son fuerzas que se relacionan cuerpo a cuerpo; permanentemente se renuevan en un acontecimiento musical: cada recorrido produce una variación de receptividades tanto en el cuerpo Artaud como en el 'tono cósmico' en el que se expresa la Sierra:

Por todas partes me parecía estar oyendo una historia de alumbramientos en la guerra, una historia de génesis y de caos, con todos aquellos cuerpos de dioses cortados como hombres y aquellas estatuas humanas troceadas. Ni una sola forma estaba intacta, ni un solo cuerpo dejó de parecerme como salido de una reciente matanza, ni un solo grupo en el que no leyese la lucha que lo dividía (1977: 37).

La relación permanente entre fuerzas hace parte de un mismo acontecimiento, a saber: el proceso de exterminio y de curación orgánica del espíritu de Artaud; su agenciamiento compone toda una armonía precedida por el caos, es decir, por el cataclismo orgánico que produce la toma de peyote; pero aunque las fuerzas despertadas sean caóticas, el filtro de esas fuerzas, el CsO, permite una expresión de la materia que retrotrae la sensación de caos a una experiencia cósmica, inorgánica, en relación con Ciguri. Se destruye un territorio para construir uno nuevo: un espacio se descodifica (la conciencia y los símbolos de Occidente) en la sobrecodificación de otro (la Sierra y los símbolos tarahumara).

Artaud percibe los signos y los desplaza en el movimiento de su cuerpo. Dentro de la cultura tarahumara las cruces son signos valiosos; no tienen que ver con la cruz católica; la cruz tarahumara cifra un espacio donde se disuelve el Hombre en puntos 
cardinales que lo comunican con el cosmos; en ese sentido, las cruces tarahumara anuncian la propia crucifixión de Artaud. El Hombre es un principio diverso en el territorio; figuras informes, potencias, intensidades y sensaciones son las que vienen a configurar el contenido de la materia de expresión de un Hombre "cuarteado" en el espacio. En cierto modo, esta disposición perceptiva de antemano es producida por elCsO; pero, más allá de la pura percepción, el plano de inmanencia del CsO indica un tipo de pensamiento figural ${ }^{3}$ donde se articula el conjunto de signos propios de la cosmovisión tarahumara:

Cada poblado tarahumara está precedido por una cruz y rodeado de cruces en los cuatro puntos cardinales de la montaña. No es la cruz de cristo, la cruz católica, es la cruz del Hombre cuarteado en el espacio, el Hombre con los brazos abiertos, invisible, clavado a los cuatro puntos cardinales. Con ello los tarahumaras manifiestan una idea del mundo geométrica y activa, a la que la propia forma del Hombre está unida (1977: 75).

Artaud produce una combinación de signos, genera una relación de fuerzas y de sensaciones en concordancia con la experimentación del CsO; de ahí la singularidad de sus descripciones. La vuelta sobre sí, o el círculo que se genera en el proceso de desterritorialización y de territorialización, no se resuelve nunca por la extensión temporal y lineal de la historia, sino por la intensidad con la que experimenta el $\mathrm{CsO}$. ElCsO siempre vuelve en un acontecimiento que no se repite: siempre permite que algo ocurra con la materia que se expresa desde su propio territorio; en pocas palabras, se puede llamar a este tipo de producción escenopoiética, pues, al quedar expuesto a la experimentación, el CsO se convierte en la potencia de esas intensidades, de esas sustancias y de esas fuerzas que se expresan en las figuras que van cifrando el territorio: "La tierra ya no es una fuerza entre otras, ni una sustancia informada o un medio codificado, que tendría su momento y su parte. La tierra ha devenido ese cuerpo a cuerpo de todas las fuerzas, tanto las de la tierra como la de las otras sustancias" (2010: 343) .

3 Aunque el concepto provenga de Lyotard, me atengo al sentido que le otorga Adolfo Chaparro al plantear un "pensar por figuras", y no por conceptos, que tendría su plano de consistencia en un tipo de cosmovisión que organiza los distintos aspectos dela vida social y personal, y no propiamente en un logosen el sentido griego (2013: 137).

4 En ese sentido, los números y la música son también elementos de un ritornelo cósmico propio de la Sierra. En el mismo relato se puede encontrar lo siguiente:

"Hay en la Cábala una música de los Números, y dicha música, que reduce el caos material a sus principios, explica mediante una especie de matemática grandiosa, cómo se ordena la Naturaleza y cómo dirige el nacimiento de las formas, que saca del caos. Y todo lo que 
En síntesis, el territorio se compone en la multiplicidad de espacios cifrados que se expresan en la continua repetición y variación de los signos, y que terminan por doblar el espacio con las figuras que lo compone en sus pliegues, extensiones y distanciamientos. En el recorrido por esos espacios, el CsO produce ritmos y capta líneas de fuerza dentro de la geografía de la Sierra; permite la proliferación de perceptos figurativos y táctiles; se construye a partir de una diversidad de continuums de intensidades (2010: 75); agencia todo un proceso de individuación dentro del socius tarahumara: comanda por un momento el sentido de una colectividad territorializada y en proceso de desterritorialización; asume el lenguaje de esa colectividad para acceder a esa instancia en que la Naturaleza "habla a lo largo de toda la extensión geográfica de una raza" (1977: 35).

\section{LAINSCRIPCIÓN MAQUíNICA Y LA CLAUSURA DE LA REPRESENTACIÓN}

La experiencia con los tarahumaras inscribe una huella de tal intensidad en la conciencia de Artaud que siguió incidiendo a lo largo de su producción poética y escritural; la máquina expresiva que empieza a gestarse en el continente amerindio despliegatoda una práctica artística de regreso a Europa. De hecho, el texto Los Tarahumaras está escrito fragmentariamente, fue un trabajo que le tomó casi unos doce años (1977: 136), pero no porque quisiera concluir 'el libro', sino porque aquellos perceptos del $\mathrm{CsO}$ volvían con distinta intensidad, y no dejarían de influir tanto en la salud mental como en la salud corporal del propio Artaud; en efecto, los signos tarahumara vuelven como acontecimiento en su repetición, y se puede registrar su huella en textos que van del 36 hasta el47, un año después de salir de la clínica de Rodez, y un año antes de morir de cáncer en la clínica psiquiátrica de Ivry ${ }^{5}$.

El agenciamiento maquínico derivó en la clausura de la representación. En 1938 aparece El Teatro y su doble, dos años después del viaje a la Sierra; sin duda, es un texto altamente influenciado por su experiencia con los tarahumaras; en él plantea un teatro que rompiera con el recurso de la representación como principio de creación

veía me parecía obedecer a una cifra. Las estatuas, las formas, las sombras, daban siempre un número 3, 4, 7, 8, que reaparecía. Los bustos de las mujeres troceados eran 8; el diente fálico, como ya he dicho, tenía tres piedras y cuatro agujeros; las formas volatilizadas eran 12, etc. Repito, se puede decir que dichas formas son naturales, de acuerdo; pero lo que no es natural es su repetición. Y lo que es todavía menos natural es que los tarahumaras reproduzcan las formas de su país en sus ritos y en sus danzas" (1977: 38).

5 Textos como Van Gogh el suicidado de la sociedad y El momo pueden dar testimonio de ello. 
escénica. El Teatro de la Crueldad que propone Artaud le apuesta al drama y al sacrificio de la vida, le apuesta al acontecimiento ritual escénico, a la destrucción del teatro occidental, a la inmersión poética de una vida ya poseída por una animalidad creadora: "El Teatro de la Crueldad ha sido creado para devolverle al teatro una concepción de la vida apasionada y convulsiva; y en ese sentido de violento rigor, de extrema condensación de los elementos escénicos, ha de entenderse la crueldad de este teatro" (1999: 139). En el fondo, la clausura de la representación apunta a la ruptura con la idea del Hombre y el Arte modernos. Teatro contra la metafísica y la narrativa de la historia.

Escrito en tono de manifiesto, El Teatro y su doble rechaza las obras maestras del teatro clásico, se resiste a la simplicidad y cordura de la moral escénica, reniega de la bestialidad del nacimiento, explora el sacrificio como flujo de una potencia revitalizadora, en fin, afirma la necesidad de explorar otras formas de vida. Es de los primeros textos del arte contemporáneo que piensa el arte como acontecimiento radical, que pretende destruir el juicio de Dios y crear otra conciencia para el hombre. Pero no por ello crea un teatro del inconsciente; antes bien, se trata de un teatro que expone la conciencia con todo rigor al asesinato, esto es, al sacrificio de los símbolos heredados. Pero más allá del teatro, lo que está en juego es el pensamiento: "La crueldad es la consciencia, la lucidez expuesta" (Derrida, 1989: 332). Su máquina de producción es, bajo esta inversión valorativa, el inconsciente, porque justamente fabrica un deseo que se expone alcontinuum de las intensidades como objeto del pensamiento: "Mi agregado de conciencia está roto. He perdido el sentimiento del espíritu, de lo que es propiamente pensable, o lo pensable en mí se arremolina como un sistema absolutamente separado, y luego vuelve a su sombra" (Artaud, 2005: 79).

Ahora, poesía y teatro no se desligan de la necesidad de explorar otras formas de vida; ambos constituyen una suerte de realismo cruel donde se disloca (y se expone) la conciencia, operando una deconstrucción radical del sujeto y de sus formas de pensar. El espacio poético-teatral se vuelca en la construcción ritual de un territorio y de un espíritu. La huella del viaje a los tarahumara se repite, desterritorializándose permanentemente; en cierto sentido, se trata de una necesidad afectiva de transformación, como si estuviera cumpliendo de forma dolorosa y plena las intenciones plasmadas en las memorias previas al viaje:

Si uno pudiera probar solamente su nada, si uno pudiera reposar en su nada y que esa nada no fuera una cierta forma de ser, pero tampoco la muerte total. 
Es tan duro dejar de existir, dejar de estar dentro de algo. El verdadero dolor es sentir cómo se desplaza nuestro pensamiento en uno mismo. Pero el pensamiento como un punto no es seguramente un sufrimiento.

Estoy en el instante en el que no me aferro más a la vida, pero llevo conmigo todos los apetitos y las insistentes titilaciones del ser. No tengo más que una ocupación: volverme a hacer (Artaud, 2002: 64).

Utilizando los términos de Deleuze y Guattari, se puede decir que Artaud es un esquizo experimental: su $\mathrm{CsO}$ es una especie de síntesis conectiva de conjuntos intensos y heterogéneos que se redefinen desde su inscripción en el conjunto de prácticas y valores tarahumara. Sin embargo, el proceso de construcción del CsO siempre compone máximos de desterritorialización de las pulsiones del mismo Artaud. Es una máquina que produce deseo a partir del conjunto de intensidades que lo atraviesan, donde pulsión de muerte (sacrificio) y principio de placer (recomposición) actúan simultáneamente. Estas pulsiones no dejan de "aproximarse a su límite, que es un límite propiamente esquizofrénico” (Deleuze \& Guattari, 1974: 40). El límite de ese deseo se consuma en el ritual: en la aurora del nacimiento. Agenciamiento doble de la máquina; la máquina potencia tanto el viaje de Artaud como el ritual tarahumara. En la comunidad, la máquina tiene que ver con la voluntad cósmica que potencia los cuerpos. En Artaud se trata de una máquina que fabrica intensidades de deseo-pensamiento; la conjunción de las intensidades y de las máquinas lleva al límite la destrucción de los símbolos heredados, pero la máquina tiene una dimensión expresiva que hace de la experimentación un trabajo de recomposición de sía partir de una aceptación radical de la alteridad cósmica y social de los tarahumara.

"Volverme a hacer" es por eso también la consigna de una revolución interna que busca la alteridad radical, la afirmación de un dinamismo interno expuesto a fuerzas externas completamente otras. Se arriesga la conciencia y el cuerpo en la escritura y el teatro, entendidos como la afirmación dolorosa de la vida. No existen metáforas ni alegorías, solo el devenir en la experiencia. La máquina no se limita a la representación de una trama, por el contrario, no cesa de expresar un deseo que trasciende en la revitalización de los cuerpos. La huella de un agenciamiento maquínico que no cesa de producirse como escritura sobre el espacio. La escritura opera como clausura de la representación. Aquí se condensa toda la fuerza teatral de su poesía. Cuerpo y consciencia se fragmentan simultáneamente en la experiencia; ambos forman un solo corpus experimental de pensamiento y poesía vital. 


\section{REFERENCIAS}

Artaud, Antonin. (1977). Los tarahumaras. Barcelona: Barral.

Artaud, Antonin. (1999). El teatro y su doble. Barcelona: Edhasa.

Artaud, Antonin. (1973). Mensajes revolucionarios.Madrid: Fundamentos.

Artaud, Antonin. (2002). El pesa-nervios. Madrid: Visor.

Artaud, Antonin. (2005). El arte y la muerte/Otros escritos. Buenos Aires: Caja Negra.

Artaud, Antonin. (2011). Van Gogh el suicidado de la sociedad.Madrid: Fundamentos.

Chaparro, Adolfo. (2013). "Tanatoantropogénesis del pensar caníbal” y "Pensar por figuras", en:Pensar Caníbal. Buenos Aires: Katz.

Deleuze. G, \& Guattari, F. (2010). "La Geología de laMoral”, “Cómo hacerse un Cuerpo sin Órganos?” y "El Ritornelo", en:Mil Mesetas, capitalismo y esquizofrenia. Valencia: Pre-Textos.

Deleuze. G, \& Guattari, F. (1974). "Máquinas deseantes”, en:El Anti-Edipo, capitalismo y esquizofrenia.Barcelona: Barral.

Deleuze. G, \& Guattari, F. (2013). ¿Qué es la filosofía?Barcelona: Anagrama.

Derrida, Jacques. (1989). "El teatro de la crueldad y la clausura de la representación", en:La Escritura y la Diferencia. Barcelona: Anthropos. 